\title{
Histometric studies on cellular infiltrates of tuberculin tests in patients with sarcoidosis
}

\author{
J G Lowe, J H Gibbs, R C Potts, J L Stanford, J Swanson Beck
}

\begin{abstract}
The density and microanatomical location of CD4 and CD8 lymphocytes and of monocytes/macrophages at the site of a tuberculin test were measured in 13 patients with sarcoidosis, and the results were compared with those seen in a group of healthy controls. The cellular infiltrate was significantly reduced in the sarcoid subjects compared with the controls for all cell phenotypes studied; the ratio of CD4 positive:CD8 positive lymphocytes was significantly increased in the sarcoid group. Clinically negative reactions showed substantial numbers of infiltrating mononuclear cells, although not as great as in clinically apparent reactions.
\end{abstract}

A clinically negative tuberculin reaction does not necessarily imply anergy to the test substance and should not be termed "negative".

It is widely accepted that patients with sarcoidosis have a generally lower ability to acquire and express delayed hypersensitivity. ${ }^{1}$ This has been a subject of much investigation over the past 40 years, but the published evidence of this immunological impairment has not been overwhelming, and has indeed been partly conflicting. For example, it is still quoted that the tuberculin test is negative in sarcoidosis, ${ }^{2}$ although reports have, in fact, shown a wide variation in tuberculin sensitivity, probably due to many factors, including differences in testing techniques, doses used, antigen potency, and populations tested. ${ }^{3}$ A reduced level of tuberculin sensitivity has been found when patients have been compared directly with healthy controls in some studies, ${ }^{3}$ but this has by no means been a universal finding, ${ }^{4}$ and the lowered sensitivity can be restored in many subjects by using a "depot" preparation of tuberculin ${ }^{56}$ or by the addition of cortisone, ${ }^{7}$ both of which are thought to prolong the retention of tuberculin at the site of injection, and the latter to suppress the effects of suppressor cells.

It has also been reported that sarcoid patients are unable to develop or maintain skin sensitivity to tuberculin after BCG vaccination $^{8}$ whereas others have stated that BCG vaccination in sarcoid patients with primary tuberculin anergy may be as effective as in normal persons. 9 The incidence of contact allergy to some sensitisers is also reduced, although stronger agents cause similar sensit- isation in control and sarcoid subjects. ${ }^{10}$ Testing to other common skin antigens has shown significantly fewer reactions to some of these, but not to all. ${ }^{11}$ Furthermore, in vitro lymphocyte reactivity to mitogenic stimuli is not consistently and characteristically diminished in sarcoid subjects. ${ }^{12}$

Thus the overall impression is not one of total anergy, but rather of a modest lessening of the ability to mount a clinically apparent reaction to an antigenic challenge, although the intrinsic ability to react is maintained. The nature of this impairment has yet to be elucidated. Suggestions have been made that the inability to react to dinitrochlorobenzene (DNCB) in active sarcoidosis ${ }^{13}$ and normal intradermal response to phytohaemagglutinin $(\text { PHA })^{14}$ point to an afferent limb defect, whereas failure to respond to intradermal injection of supernatants of mitogen stimulated lymphocyte cultures (containing a cocktail of lymphokines) ${ }^{15}$ has suggested a "block" in the expression of delayed hypersensitivity distal to lymphocyte function-that is, in the efferent limb of the reaction.

Gibbs et al have devised a simple histometric method for quantitative analysis of the histological localisation of immunocompetent cells within the tuberculin reaction ${ }^{16}$ which allows a more comprehensive study to be made of immunological effector mechanisms than is possible by both macroscopic and routine microscopic techniques. We used this method to compare the nature of the cellular infiltrate within tuberculin reactions in a group of sarcoid patients with that of a control group of healthy subjects, with the aim of gaining insight into the kinetics of the presumed impaired hypersensitivity response of the former. Skin tests were also performed with four other mycobacterial antigens in the sarcoid subjects as profound hyporeactivity has been found to similiar mycobacterial antigens in the past. ${ }^{17}$

\section{Methods}

Thirteen subjects with sarcoidosis (age 35-64, mean 46.8 ) were recruited into the study. Approval was gained from the local ethical committee, and the participants all gave informed consent to the study. Sarcoidosis was diagnosed in seven subjects on the basis of positive histology and radiological evidence of pulmonary disease, in three by radiological evidence and positive Kveim test, in two by the combination of erythema nodosum and hilar adenopathy, and in one by radiological evidence alone. Five subjects showed objective 
Table 1 Clinical and laboratory data of sarcoidosis subjects

\begin{tabular}{|c|c|c|c|c|c|c|c|c|c|c|}
\hline No & Sex & $\begin{array}{l}\text { Age } \\
(y)\end{array}$ & $\begin{array}{l}\text { Duration } \\
(y)\end{array}$ & $\begin{array}{l}\text { Positive } \\
\text { histology }\end{array}$ & $\begin{array}{l}\text { Kveim } \\
\text { test }\end{array}$ & $\begin{array}{l}\text { Chest } \\
\text { x ray }\end{array}$ & Other findings & $\begin{array}{l}\text { Activity at } \\
\text { study }\end{array}$ & $\begin{array}{l}E S R \\
(\mathrm{~mm} / \mathrm{h})\end{array}$ & $\begin{array}{l}S A C E \\
(\mu \mid m l)\end{array}$ \\
\hline $\begin{array}{l}1 \\
2 \\
3 \\
4\end{array}$ & $\begin{array}{l}M \\
M \\
M \\
M\end{array}$ & $\begin{array}{l}44 \\
38 \\
64 \\
58\end{array}$ & $\begin{array}{r}5 \\
4 \\
19 \\
9\end{array}$ & $\begin{array}{l}\text { Lymph node } \\
\text { Lymph node } \\
\overline{\text { Skin }} \\
\text { Bronchus }\end{array}$ & $\overline{-}$ & $\begin{array}{l}\text { I } \\
\text { I } \\
\text { II } \\
\text { III }\end{array}$ & $\begin{array}{l}\text { Parotid glands } \\
\text { Uveitus } \\
-\end{array}$ & $\begin{array}{l}\text { Lymph nodes } \\
\text { Lymph nodes } \\
\text { CXR I } \\
\text { CXR III }\end{array}$ & $\begin{array}{r}51 \\
40 \\
42 \\
5\end{array}$ & $\begin{array}{l}56 \cdot 9 \\
93 \\
24 \cdot 7 \\
59 \cdot 8\end{array}$ \\
\hline $\begin{array}{l}5 \\
6 \\
7 \\
8 \\
9\end{array}$ & $\begin{array}{l}\mathrm{F} \\
\mathrm{M} \\
\mathrm{F} \\
\mathrm{F} \\
\mathrm{F}\end{array}$ & $\begin{array}{l}42 \\
35 \\
45 \\
41 \\
48\end{array}$ & $\begin{array}{r}9 \\
10 \\
4 \\
1 \\
2\end{array}$ & $\begin{array}{l}\overline{\text { Lung }} \\
\text { Lung } \\
\overline{\text { Bronchus }}\end{array}$ & $\begin{array}{l}\text { Neg } \\
\text { Neg } \\
\overline{-} \\
\text { Pos }\end{array}$ & $\begin{array}{l}\text { III } \\
\text { III } \\
\text { II } \\
\text { I } \\
\text { II }\end{array}$ & $\begin{array}{l}\overline{-} \\
\text { Uveitis } \\
\text { Erythema nodosum } \\
\text { Lymph nodes } \\
\text { Episcleritis }\end{array}$ & $\begin{array}{l}\text { CXR III } \\
\text { Nil } \\
\text { Nil } \\
\text { Nil } \\
\text { Nil }\end{array}$ & $\begin{array}{r}12 \\
8 \\
3 \\
6 \\
20\end{array}$ & $\begin{array}{l}\overline{26} \\
\overline{24} \cdot 1 \\
37 \cdot 3\end{array}$ \\
\hline $\begin{array}{l}10 \\
11 \\
12 \\
13\end{array}$ & $\begin{array}{l}\mathbf{F} \\
\mathbf{F} \\
\mathbf{F} \\
\mathbf{F}\end{array}$ & $\begin{array}{l}48 \\
62 \\
48 \\
35\end{array}$ & $\begin{array}{r}10 \\
3 \\
2 \\
5\end{array}$ & $\begin{array}{l}\text { Lymph node } \\
- \\
-\end{array}$ & $\begin{array}{l}\text { Pos } \\
\text { Pos } \\
\text { Pos } \\
-\end{array}$ & $\begin{array}{l}\text { I } \\
\text { I } \\
\text { I } \\
\text { I }\end{array}$ & $\begin{array}{l}\text { Erythema nodosum } \\
\text { Erythema nodosum }\end{array}$ & $\begin{array}{l}\text { Nil } \\
\text { Nil } \\
\text { Nil } \\
\text { Nil }\end{array}$ & $\begin{array}{r}5 \\
11 \\
15 \\
10\end{array}$ & $\frac{\overline{37} \cdot 4}{25 \cdot 7}$ \\
\hline
\end{tabular}

$\mathrm{CXR}=$ chest $x$ ray picture

evidence of disease activity and eight did not at the time of study. One patient gave a history of treated pulmonary tuberculosis 18 years previously and one had radiological evidence of calcified scarring on chest $x$-ray picture. Eight had been treated with systemic corticosteroids in the past, but none for at least four months before the study. Table 1 outlines the clinical details of the sarcoid subjects.

Skin tests were performed on the volar aspect of the forearm by intradermal injection of $0.1 \mathrm{ml}$ tuberculin purified protein derivative (PPD, Evans Medical Ltd, Middlesex, England) 1/1000 and four "new tuberculins" prepared from ultrasonically disrupted Mycobacterium tuberculosis (Tuberculin), $M$ leprae (Leprosin A), M vaccae (Vaccin) and $M$ scrofulaceum (Scrofulin). ${ }^{18}$ The reactions were inspected after 48 hours and the extent of erythema and induration measured in two perpendicular diameters.

A biopsy specimen was then taken from the centre of each New Tuberculin injection site under local anaesthesia with $2 \%$ plain Lignocaine using a $4 \mathrm{~mm}$ skin punch (Stiefel Laboratories Ltd, Slough, England). The core of tissue was bisected perpendicular to the epidermal surface, with one half being fixed in $4 \%$ neutral buffered formaldehyde for resin embedded histopathological study, and the other half snap frozen for immunocytochemical localisation of lymphocyte subsets and accessory cells. Cryostat sections ( $5 \mu \mathrm{m})$ were treated with commercial monoclonal antibodies (Becton Dickinson, Sunnyvale, California, USA) to localise CD4 + and CD8 + lymphocytes and monocytes/macrophages, followed successively with the Vectastain kit containing biotinylated antimouse immunoglobulin, the third stage reagent avidin-biotinylated peroxidase (Sera Lab Ltd, Crawley Down, Sussex, England); and finally the markers were labelled with a brown reaction product by a histochemical method using diaminobenzene.

Table 2 Clinical reactions to mycobacterial antigens

\begin{tabular}{llllll}
\hline & $P P D$ & New Tuberculin & Leprosin A & Scrofulin & Vaccin \\
\hline Negative & 5 & 6 & 10 & 10 & 6 \\
$>5$ mm erythema & $8(31)$ & $5(21)$ & $3(10)$ & $3(9)$ & $6(12)$ \\
$>5$ mm induration & $5(20)$ & $3(15)$ & 0 & $1(12)$ & $2(15)$ \\
\hline
\end{tabular}

Number of patients showing negative, erythematous, or indurated reactions to each antigen (figures in parentheses are mean diameter of the reactions in $\mathrm{mm}$ ).
Monochrome photographic prints were then taken of each section to permit quantitative assessment of the cellular infiltrate. The margins of the perivascular foci were delineated with a felt pen, and the cells were counted by direct inspection in the foci and intervening tissue. The areas of the foci and intervening tissue were then measured by cursor planimetry in a semiautomatic apparatus (Imagan Graphics Information Systems, Blairgowrie, Scotland), allowing the densities to be calculated, expressed as number $/ \mathrm{mm}^{2}$. The details of these methods have been reported previously. ${ }^{16}$

A group of 13 healthy control subjects (age 16-53, mean 38.2 ) were similarly skin tested with New Tuberculin antigen, informed consent having been given. Biopsies at 48 hours and subsequent analysis were performed as for the sarcoid group.

Statistical analysis was performed using Student's $t$-test.

\section{Results}

Table 2 summarises the macroscopic appearance of reactions to the various mycobacterial antigens in the sarcoid subjects. As in a previous report of a comparable study in patients with chronic obstructive airways disease, ${ }^{19}$ few indurated reactions were seen with either Leprosin A or Scrofulin in our northern European subjects, and the PPD reactions tended to be larger than those due to New Tuberculin. The overall responses of the sarcoid group were not appreciably different from the subjects with chronic obstructive airways disease (COAD), and notably only three of the 13 sarcoid subjects showed no visible reaction to all five antigens, whereas this was the case with eight of the 15 COAD group.

Table 3 compares the responses to New Tuberculin in the sarcoid patients with that seen in the controls. Although more than half of the sarcoid subjects were able to mount clinically apparent reactions to this antigen, overall, the reactions were considerably stronger in the control group. Nevertheless, three of the sarcoid subjects did have strongly positive reactions; two of these were considered to have inactive disease, but the other had active disease in lymph nodes, toe, and turbinate.

The proportion of the skin biopsy specimen 
Table 3 Clinical reactions to New Tuberculin

\begin{tabular}{lcl}
\hline & Control & Sarcoidosis \\
\hline Negative & 1 & 6 \\
$>5 \mathrm{~mm}$ erytherna & $1(9)$ & $5(21)$ \\
$>5 \mathrm{~mm}$ induration & $11(15)$ & $3(15)$ \\
\hline Numbers of patients showing negative, erythematous, or \\
indurated reactions to New Tuberculin (figures in parentheses \\
are mean diameter of the reactions in mm).
\end{tabular}

occupied by the focal perivascular infiltrates, and the overall density of the $\mathrm{CD} 4+$ and CD8 + lymphocyte subsets and monocyte/ macrophages throughout the section are shown in fig 1 . It is apparent that, as might be expected from the clinical reactions, the sarcoid subjects had a significantly smaller area occupied by the focal perivascular infiltrates and less dense infiltrates of all three cell types; the reduction in each type of cell was significant in both focal and diffuse compartments except for the density of monocytes/macrophages in the focal infiltrate.

Figure 2 shows the $\mathrm{CD} 4+: \mathrm{CD} 8+$ ratios throughout the section as a whole as well as within the focal and diffuse compartments. The ratio has significantly increased throughout the section $(p=0.005)$, principally due to the diffusely infiltrating cells in the sarcoid group.

The cellular content of clinically negative and positive reactions (erythematous as well as indurated) of the sarcoid subjects are compared in fig 3. There is an increase in both the size of focal inflammatory infiltrate as well as the cellular densities of all three cell types in the positive reactions, although the negative reactions also showed substantial areas of focal inflammation and cellular infiltrates, in some

Figure 1 Proportion of occupied by focal infiltrate $(p=0.005)$ and density of $(B) C D 4$ positive $(p=0.0002)$ and $(C)$ $C D 8$ positive

$(p=0.0002)$

lymphocytes and $(D)$ monocytes/macrophages $(p=0.002)$ throughout the section in control and sarcoid subjects.

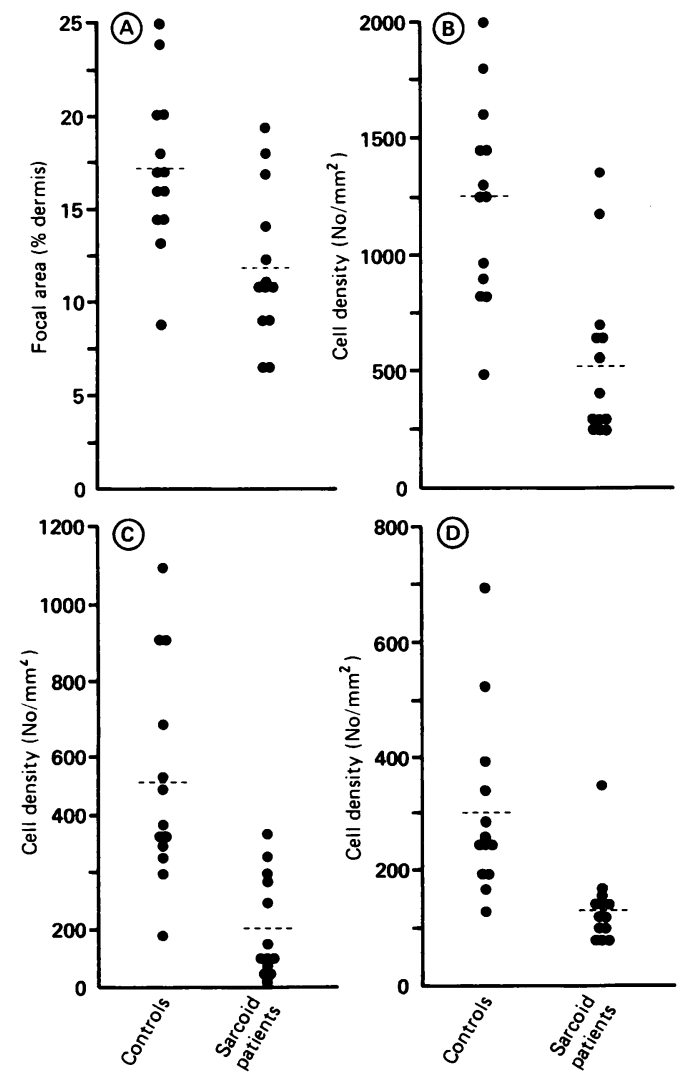

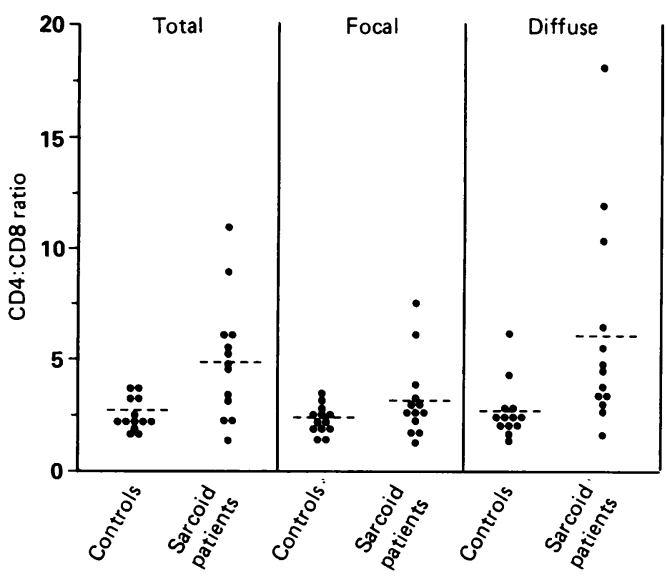

Figure $2 C D 4$ positive: $C D 8$ positive lymphocyte ratios in control and sarcoid subjects: total (throughout the section, $p=0.005$ ), focal perivascular (NS) and diffuse $(p=0.02)$ compartments.

cases greater than in the clinically apparent reactions. Comparison of the active and inactive disease subjects in terms of focal infiltrate, overall monocyte/macrophage and lymphocyte density, and $\mathrm{CD} 4+: \mathrm{CD} 8+\mathrm{T}$ lymphocyte ratios shows no appreciable difference between the two groups.

\section{Discussion}

There is a high ratio of helper to suppressor phenotypes of the $T$ lymphocytes in sarcoid granulomas $^{20}$ and there seems to be a redistribution of predominantly helper related phenotype $T$ lymphocytes to the sites of disease activity with consequent depletion of these cells in the blood. ${ }^{21} \mathrm{~A}$ previous study has shown that PPD injection sites of sarcoid patients contain fewer $T$ cells than control infiltrates of PPD positive healthy subjects with a relatively low proportion of $\mathrm{T} 4+$ cells, suggesting a relative deficiency of the inducer type immunoregulatory influences. It was therefore thought that the PPD anergy may be due to the sluggish traffic of $\mathrm{T} 4+$ cells due to their sequestration in sites of ongoing inflammation. ${ }^{22}$ We have confirmed that the tuberculin test sites in our sarcoid patients contain a lesser cellular infiltrate compared with controls, but we have not found evidence of relative deficiency of the CD4 + lymphocyte subset. Indeed, our sarcoid subjects showed a significantly higher proportion of this phenotype compared to the control group. This ratio of 5:1 in the sarcoid group is similar to that found in lesions of cutaneous sarcoidosis, ${ }^{20}$ suggesting that the lymphocytes react in a similar manner to the tuberculin antigen as they do to the activating factor of the disease process.

There is a difference of 8.6 years between the mean ages of the sarcoid and control subjects, but we do not feel that this can explain the differences in results between the two groups. The presence or absence of objective evidence of disease activity had no appreciable effect on the histometric analysis in our sarcoid subjects. This finding is in keeping with the studies of Chusid and Israel, ${ }^{23}{ }^{24}$ who found little influence by the course of the sarcoidosis on tuberculin 
Figure 3 Proportion of skin biopsy specimen occupied by $(A)$ focal infiltrates and density of (B) CD4 positive and (C) $C D 8$ positive lymphocytes and (D) monocytes/macrophages throughout the section in negative, erythematous and indurated reactions of sarcoid subjects.
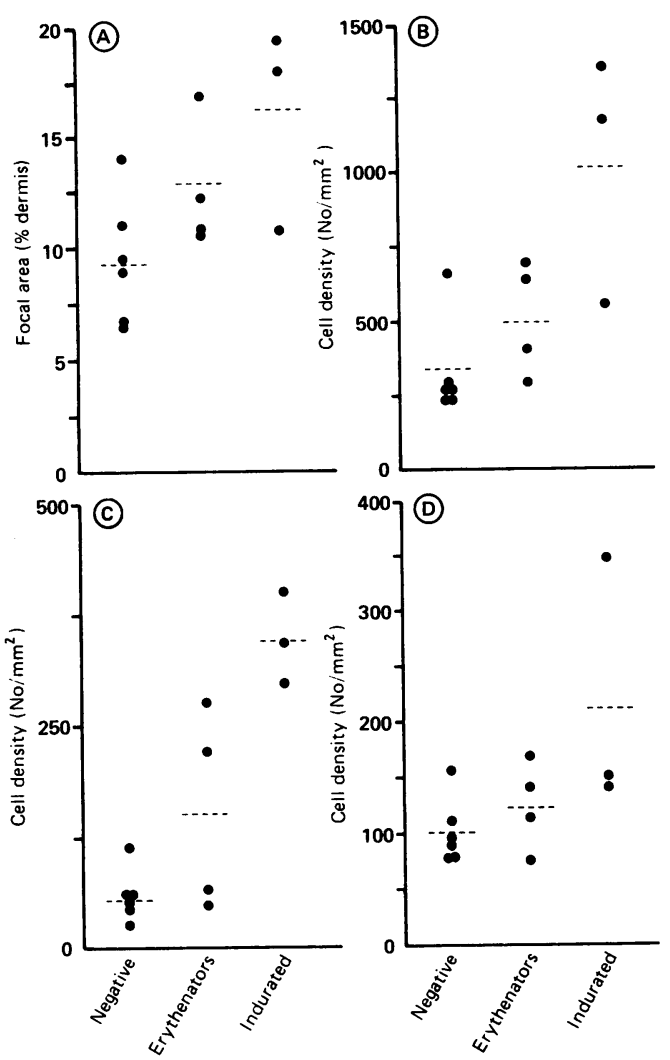

sensitivity. This may mean that patients apparently free of disease have in fact ongoing undetected activity, or perhaps that the basic immunological defect persists without being manifest as clinical disease.

As long ago as 1948, Schaumann and Seeberg ${ }^{25}$ noted that clinically negative Mantoux skin test sites showed considerable histopathological changes four to eight weeks after injection. Perivascular infiltrates of up to 250 cells per high power field were also seen 48 hours after injection at PPD skin test sites in the absence of erythema or induration by Mishra et al in $1983 .^{22}$ These cells were mostly lymphocytes interspersed with small numbers of macrophage-like cells. Our study has confirmed that substantial numbers of inflammatory cells can be present at the site of clinically negative tuberculin reactions of sarcoidosis subjects, and this has also been observed by us in patients with chronic obstructive airways disease treated with prednisolone ${ }^{19}$ mycobacterial disease ${ }^{26}$ and haemophilia. ${ }^{27}$ It is not clear how this subclinical inflammation (or "pseudoanergy") should be interpreted, but may indicate that these subjects are basically tuberculin-sensitive in that antigen deposition in tissue is able to evoke lymphocyte and monocyte emigration from the microcirculation, but that the emigration does not liberate sufficient mediators to cause clinically apparent vasodilatation and oedema. This is supported by the finding that depot preparations of tuberculin are able to convert negative to positive reactions in patients with sarcoidosis, ${ }^{56}$ perhaps due to the persistent antigen being able to attract greater numbers of inflammatory cells to the reaction site with consequent increased mediator release. This suggests that the defect lies not in the afferent limb of the reaction, but rather in the sluggish emigration of cells in the efferent arm.

Thus in patients with sarcoidosis intradermal injection of New Tuberculin is able to provoke a delayed hypersensitivity reaction which is visible microscopically if not clinically, and the pattern of lymphocyte recruitment is similar to sites of disease activity with preponderance of the CD4 + subset. Our findings of only three sarcoid subjects clinically unreactive to all five antigens along with a significant reduction in numbers of infiltrating cells, which can nevertheless be present in substantial numbers, are consistent with the report of Hoyle, ${ }^{3}$ who noted that, "depression of (tuberculin) sensitivity is not an all-or-none reaction but an alteration in the level of sensitivity, which is lowered in most cases of sarcoidosis".

It is known that the Kveim test, which is so often used to substantiate a diagnosis of sarcoidosis, can show granulomatous features in the absence of any clinically observable erythema or induration, and thus a biopsy specimen is considered essential to establish the diagnosis $;^{28}$ even on histopathological examination however, discordant readings occur, and Scadding has suggested that the "positive-negative" terminology should be avoided, and that descriptive terms should be used instead. ${ }^{29}$ There is a parallel situation with tuberculin tests, and although we would not suggest routine biopsy as for Kveim tests, perhaps we should also avoid the "positive-negative" terminology and instead use descriptive terms. "No clinical reaction" appears to us a more appropriate term than "negative", since in many cases the underlying tissue may be the seat of considerable cellular activity.

We are grateful to Dr R N Johnston for access to the sarcoidosis patients, to Mr R S Fawkes and Mrs Sheila Gibbs for preparing the diagrams and to Ms Maureen Hughes for valuable secretarial assistance.

1 Scadding JG, Mitchell DN. Sarcoidosis. London: Chapman and Hall, 1985:414.

Kuramoto $Y$, Tagami $H$. Histopathologic pattern analysis of human intracutaneous tuberculin reaction. $\mathrm{Am} J \mathrm{Der}-$ matopathol 1989;11:329-37.

3 Hoyle C, Dawson J, Mather G. Skin sensitivity in sarcoidosis. Lancet 1954;ii:164-8.

4 Sutherland I, Mitchell D, D'Arcy Hart P. Incidence of intrathoracic sarcoidosis among young adults participating in a trial of tuberculosis vaccines. $\mathrm{Br}$ Med 1965;2:497-503.

5 Seeberg G. Tuberculin sensitivity in lymphogranulomatosis benigna. Acta Dermatol Vener 1951;31:426-34.

6 James DG, Pepys J. Tuberculin in aqueous and oily solutions. Lancet 1956;i:602-4.

7 Citron KM, Scadding JG. The effect of cortisone upon the reaction of the skin to tuberculin in tuberculosis and in sarcoidosis. Q J Med 1957;26:277-89.

8 Israel $\mathrm{HL}$, Sones M, Stein SC, et al. BCG vaccination in sarcoidosis. Am Rev Tub 1950;62:408-17.

Somner E. Primary and secondary anergy in sarcoidosis. Acta Med Scand 1965(Suppl 425): 195-7.

10 Epstein WL, Mayock RL. Induction of allergic contact dermatitis in patients with sarcoidosis. Proc Soc Exp Biol dermatitis in patients

11 Sones M, Israel HL. Altered immunologic reactions in sarcoidosis. Ann Int Med 1954;40:260-7.

12 Goldstein RA, Janicki BW, Mirro J, et al. Cell-mediated immune responses in sarcoidosis. Am Rev Respir Dis 1978;117:55-62.

13 Verrier Jones J. Development of sensitivity to dinitrochlorobenzene in patients with sarcoidosis. Clin Exp Immunol 1967;2:477-87.

14 Kataria YP, Lobuglio AF, Helentjaris T, et al. Phytohemagglutinin (PHA) skin test in patients with sarcoidosis. Am 
Rev Respir Dis 1975;112:575-8.

15 Gross NJ. The paradoxical skin response in sarcoidosishypothesis. Am Rev Respir Dis 1973;107:798-801.

16 Gibbs JH, Ferguson J, Brown KA, et al. Histometric stud of the localisation of lymphocyte subsets and accessor cells in human Mantoux reactions. J Clin Pathol 1984;37 1227-34.

17 Lordon RE, Young RL, Shapiro SS, et al. Sarcoidosis-A clinical evaluation of the alteration in delayed hypersensitivity. Am Rev Respir Dis 1968;97:1009-16.

18 Anonymous. New Tuberculins. [Editorial.] Lancet 1984;i: 199-200.

19 Lowe JG, Beck JS, Gibbs JH, et al. Skin test responsiveness to four new tuberculins in patients with chronic obstructive airways disease receiving short term high doses of, or long term maintenance treatment with, prednisolone: clinical appearances and histometric studies. J Clin Patho 1987;40:42-9.

20 Modlin RL, Hofman FM, Sharma OP, et al. Demonstration in situ of subsets of T-lymphocytes in sarcoidosis. $\mathrm{Am}$ Dermatopathol 1984;6:423-7.

21 Semanzato G, Pezzutto A, Pizzolo G, et al. Immunohistological study in sarcoidosis: evaluation at different sites of disease activity. Clin Immunol Immunopathol 1984;30: $29-40$.
22 Mishra BB, Poulter LW, Janossy G, et al. The distribution of lymphoid and macrophage like cell subsets of sarcoid and Kveim granulomata: possible mechanisms of negative PPD reaction in sarcoidosis. Clin Exp Immunol 1983 54:705-15.

23 Chusid EL, Shah R, Siltzbach LE. Tuberculin tests during he course of sarcoidosis in 350 patients. Am Rev Respir Dis 1971;104:13-21.

24 Israel HL, Sones $M$. Immunologic defect in patients recovered from sarcoidosis. $N$ Engl J Med 1965;273: 1003-6.

25 Schaumann J, Seeberg G. On cutaneous reactions in cases in lymphogranulomatosis benigna. Acta Dermatol Vener lymphogranulonat

26 Beck JS, Morley SM, Gibbs JH, et al. The cellular response of tuberculosis and leprosy patients and of healthy controls in skin tests to "New Tuberculin" and Leprosin A Clin Exp Immunol 1986;64:484-94.

27 Lowe JG, Beck JS, Madhok R, et al. Histometric studies on cellular infiltrates of tuberculin tests in patients with haemophilia. J Clin Pathol 1989;42:184-7.

28 Scadding JG, Mitchell DN. Sarcoidosis. London: Chapman and Hall, 1985:459.

29 Scadding JG, Mitchell DN. Sarcoidosis. London: Chapman and Hall, 1985:463. 